\title{
Pengaruh Kompetensi,Akuntabilitas, Penerapan Kode Etik, dan Gaya Kepemimpinan terhadap Kualitas Audit di Kap di Medan
}

\author{
Namira Ulfrida Rahmi ${ }^{1}$, Tio Hadi ${ }^{2}$, Susilawati ${ }^{3}$, Widia ${ }^{4}$, Adam Fredy ${ }^{5}$ \\ $1,2,3,4,5)$ Universitas Prima Indonesia \\ namiraufridarahmi@unprimdn.ac.id, tiohadi56@gmail.com, susilawatixie3005@gmail.com, \\ widiasimic@gmail.com, adamfredy08@gmail.com
}
Diajukan
: 19 April 2021
Disetujui
: 28 April 2021
Dipublikasi
: 13 Agustus 2021

\begin{abstract}
Various cases that occurred in KAP are evidence of problems in the KAP environment that affect the quality of auditors in conducting audits. In conducting audits, independent auditors are required to observe professional principles, including professional responsibility, public interest, integrity, objectivity, competence, and professional prudence. However, various cases that arise within the Public Accounting Firm are one of the reasons for the reduced public trust in Public Accounting Firm services, one of which occurred in the case of violations committed by Hasnil M Yasin \& Partners where the director of this Public Accounting Firm committed income tax evasion. in Langkat Regency under the demands of the Public Prosecutor Service along with the Langkat regional secretary Surya Djahisa. Hasnil is suspected of committing a criminal act of corruption that resulted in a loss of state funds of 1 billion rupiahs, therefore the researchers conducted tests in assessing competence, accountability, the application of the Code of Ethics and Leadership Styles that affect the quality of audits at KAP Medan city. The population and samples were taken with the saturation technique. The data analysis model uses structural models, measurement models, path diagram designs, conversion of path diagrams into a system of equations, estimates, the goodness of fit, and others to get the desired results with the help of the WrapPls program. The results showed that the competence, accountability, and code of ethics of Medan public accountants did not affect audit quality. Leadership style has an effect on audit quality at KAP Medan City.
\end{abstract}

Keywords: Competence; Accountability; Adoption of the Code of Ethics; Leadership Style; Audit Quality

\section{PENDAHULUAN}

Kantor Akuntan Publik (KAP) adalah suatu badan usaha yang sudah memperoleh izin dari Kementrian Keuangan sebagai wadah untuk akuntan publik memberikan jasanya. Laporan audit biasanya digunakan oleh manager sebagai pihak internal untuk mengambil keputusan dalam pengembangan perusahaan. Sedangkan untuk pihak eksternal bisa digunakan untuk investor dalam mengambil keputusan investasi.

Berbagai kasus yang terjadi pada KAP menjadi suatu bukti bahwa adanya permasalahan di dalam KAP yang mempengaruhi kualitas auditor dalam melakukan audit. Hal ini yang menjadi suatu opini adanya ketidakpercayaan terhadap kualitas audit para auditor di dalam KAP. Pelanggaran terhadap kode etik profesi terkait dengan masalah audit yang terjadi di Kota Medan, yaitu masalah Pengadilan Tindak Pidana Korupsi (PN) Medan yaitu kasus Hasnil M Yasin \& Rekan, direktur kantor akuntan publik (KAP). Pada tahun 2001 dan 2002, Hasnil diduga melakukan penggelapan pajak penghasilan di Kabupaten Langkat di bawah tuntutan Jaksa Penuntut Umum (JPU) bersama dengan Sekretaris Daerah Langkat Surya Djahisa. Hasnil diduga melakukan tindak pidana korupsi yang mengakibatkan kerugian dana negara sebesar 1 miliar Rupiah. Kuasa hukum Choirun Parapat menyatakan bahwa ketika Surya Djahisa menjadi bendahara Pemerintah Kabupaten Langkat, ia memilih KAP Hasnil M Yamin \& Rekan untuk mengubah biaya PPH PPH 
Pasal 21 tahun pajak 2001 dan 2002 menjadi sama dengan tarif pajak baru. Kabupaten Langkat menerima pengembalian dana sebesar 5,9 miliar rupiah.

KAP Hasnil M Yamin \& Rekan menerima 20\% dari 5,9 miliar rupiah atau 1,19 miliar rupiah. Tersangka menerima sekitar 400 juta rupiah, dan Surya Djahisa juga menerima sekitar 793 juta rupiah. Atas perbuatan terdakwa tersebut, negara mengalami kerugian sebesar Rp1,193 miliar. Nilai nominalnya sama dengan yang dihitung oleh Badan Pengawas Keuangan dan Pembangunan (BPKP) Sumatera Utara. Mirip dengan Surya Djahisa, dalam persidangan sebelumnya, terdakwa Hasnil memanipulasi haknya untuk memperoleh lebih banyak kekayaan bagi dirinya dan orang lain. Hal ini menyebabkan perilaku etis auditor dalam audit konflik karena melanggar etika profesi dan standar audit akuntan publik.(www.tribunmedan.com).

Dalam melakukan audit, auditor independen diharuskan untuk memperhatikan prinsipprinsip profesional, termasuk tanggung jawab profesional, kepentingan publik, integritas, objektivitas, kompetensi dan kehati-hatian profesional, kerahasiaan, perilaku profesional dan standar teknis (Harjanto, 2014). Dan ikuti "Kode Etik Profesi Akuntan Publik" sebagai aturan dasar audit. Hal ini dikarenakan "Kode Etik Akuntan Publik" yang dijalankan dengan baik akan mempengaruhi kualitas hasil review. (Adi, 2016)

(Trisnaningsih, 2007) melakukan penelitian untuk mempelajari pengaruh gaya kepemimpinan dan budaya organisasi terhadap tingkat kerja dan budaya antar negara. Gaya kepemimpinan menggambarkan bagaimana atasan memberikan motivasi kepada bawahan dengan tujuan dan sasaran tertentu. Gaya kepemimpinan dapat mencerminkan perilaku auditor dan bagaimana auditor membangun hubungan dengan auditor lain dalam posisinya untuk bersama-sama meningkatkan kinerja dan menciptakan atau membentuk suasana yang harmonis.

Pemimpin yang dapat memobilisasi bawahannya dengan baik secara tidak langsung dapat memperoleh kualitas audit yang baik (Saputra, Sujana, \& Werastuti, 2015).(Fahdi, 2018) mengemukakan bahwa pengaruh kompetensi dapat berdampak positif dan signifikan terhadap kualitas audit. (Nainggolan \& Abdullah, 2016) juga melakukan penelitian mengenai pengaruh kompetensi terhadap kualitas audit.

(Dewi \& Sudana, 2018) meyakini bahwa sistem akuntabilitas berpengaruh positif dan signifikan terhadap kualitas audit. Dimana akuntabilitas merupakan sikap pertanggungjawaban seorang auditor terhadap hasil audit yang dilakukan oleh suatu perusahaan sehingga hasil audit tersebut lebih berkualitas. (Mardisar \& Sari, 2007) mengatakan bahwa kualitas hasil pekerjaan auditor dapat ditentukan oleh rasa tanggung jawab (akuntabilitas) yang dimiliki auditor dalam menyelesaikan audit pekerjaan. Oleh karena itu akuntabilitas merupakan hal yang sangat penting yang harus dimiliki oleh seorang auditor dalam melaksanakan pekerjaan agar meningkatkan kualitas audit.

Penelitian (Wardana \& Ariyanto, 2016) menunjukkan bahwa gaya kepemimpinan berpengaruh positif dan signifikan terhadap kualitas audit, namun (Purnomo, 2017) dan penelitian (Ilham, Rai, Sigit, \& Surono, 2019) membuktikan bahwa kompetensi tidak berpengaruh terhadap kualitas audit, dan (Wahyuni, 2018) juga memiliki penelitian yang menunjukkan bahwa akuntabilitas tidak berpengaruh terhadap kualitas audit.

Berdasarkan teori yang dipaparkan sebelumnya dan hasil beberapa peneliti yang terjadi menimbulkan perbedaan hasil penelitian, maka peneliti ingin menguji kembali penelitiannya, yaitu: Pengaruh Kompetensi, Akuntabilitas, Penerapan kode etik, dan Gaya kepemimpinan Terhadap Kualitas Audit Di KAP Di Medan.

\section{Teori Pengaruh kompetensi dan kualitas audit}

\section{STUDI LITERATUR}

Kompetensi auditor adalah kualifikasi yang dibutuhkan oleh seorang auditor untuk melakukan audit yang tepat. Dalam pelaksanaan audit, auditor harus memiliki kualitas pribadi yang baik, pengetahuan yang cukup, dan pengalaman kerja yang cukup (Ilmiyati \& Suharjo, 2012). Tentu saja, pengetahuan terbesar konsisten dengan peningkatan pengalaman seseorang. Pengalaman juga berdampak pada setiap keputusan yang diambil selama peninjauan, sehingga setiap keputusan adalah keputusan yang tepat (Tjun, Marpaung, \& Setiawan, 2012). Akuntan 
dengan pengalaman kerja audit dapat menjelaskan tingkat kompetensi profesionalnya dan melakukan lebih banyak audit.Kualitas Auditor (Ilmiyati \& Suhardjo, 2012)merupakan pionir dalam melaksanakan tugas audit, harus senantiasa meningkatkan pengetahuan yang telah dimilikinya agar dapat memaksimalkan pengetahuan dalam praktek dan mengikuti

Perkembangan saat ini sedang berlangsung (Dahlia \& Octavianty, 2016). Indikator kemampuan adalah (1) pengetahuan dan (2) pengalaman. Berdasarkan teori yang ada, maka dapat ditentukan hipotesis sebagai berikut:

$\mathrm{H}_{1}$ : Kompetensi berpengaruh terhadap kualitas Audit di KAP di Medan, Sumatera Utara

\section{Teori Pengaruh Akuntabilitas dan kualitas audit}

Akuntabilitas merupakan dorongan sosial dan psikologis, yaitu seseorang harus bertanggung jawab atas apa yang dilakukannya terhadap orang lain atau lingkungan. (Mardisar \& Sari, 2007)

Berdasarkan hasil (Ardini, 2010) dapat diketahui bahwa sistem akuntabilitas berpengaruh positif dan signifikan terhadap kualitas audit. Dapat ditentukan bahwa jika auditor selalu disertai dengan tanggung jawab saat melaksanakan tugas audit, Periksa laporan dengan akurasi tinggi dan lakukan upaya ke dalamnya (kekuatan berpikir)

Dalam menyelesaikan tugas audit, dan selalu berfikir terbaik saat melakukan tugas audit. (Ardini, 2010). Ada dua indikator yang dapat digunakan untuk mengukur tanggung jawab pribadi: (1) motivasi dan (2) kewajiban sosial. (Ilmiyati \& Suhardjo, 2012). Dari hasil penelitian dan landasan teori yang ada diatas, maka dapat disimpulkan hipotesis sebagai berikut:

H2: Akuntabilitas berpengaruh terhadap kualitas audit di KAP di Medan,Sumatera Utara

\section{Teori Pengaruh kode etik dan kualitas audit}

Kode Etik berdampak pada kualitas audit dalam prosesnya menuntut akuntan publik untuk menjalankan pekerjaannya sesuai dengan ketentuan yang berlaku. Dengan diterapkannya standar etika diharapkan tidak terjadi kecurangan antar auditor, sehingga dapat saling memberikan opini audit yang sebenarnya berdasarkan laporan keuangan.

Layanan yang diberikan oleh perusahaan (Adi, 2016). Demikian pula (Futri \& Juliarsa, 2014) menunjukkan bahwa penerapan kode etik berdampak positif terhadap kinerja auditor, apabila auditor tidak atau tidak mematuhi kode etik maka dia tidak akan dapat memberikan hasil yang memuaskan bagi dirinya maupun kliennya. Berikut indikator yang bisa digunakan

1. auditor dan kolega mereka

2. auditor keberatan dengan atasan mereka

3. auditor dan klien / objek inspeksi

4. auditor publik.

Berdasarkan teori yang sudah ada, maka dapat disimpulkan hipotesis sebagai berikut :

H3: Penerapan Kode Etik berpengaruh terhadap Kualitas Audit di KAP di Medan,Sumatera Utara

\section{Teori Pengaruh gaya kepemimpinan dan kualitas Audit}

Gaya kepemimpinan bertujuan untuk mendorong semangat kerja, kepuasan kerja dan efisiensi kerja karyawan yang tinggi untuk mencapai tujuan organisasi. Gaya kepemimpinan berkaitan dengan sikap atau pola perilaku pemimpin yang dapat ditiru oleh bawahannya untuk mencapai tujuan organisasi. Gibson dalam penelitian (Setiyadi, 2016) dapat menggunakan indikator gaya kepemimpinan yaitu:

1. Hubungan antara bawahan dan atasan

2. Cara pengambilan keputusan

3. Cara/sudut pandang

4. Memberi reward.

Hasil teoritis di atas didukung oleh hasil penelitian (Setiyadi, 2016) yang menunjukkan bahwa gaya kepemimpinan berpengaruh terhadap kinerja audit. Dari hasil penelitian diatas bersama dengan teori yang ada,maka dapat ditetapkan hipotesis sebagai berikut:

H4: Gaya kepemimpinan berpengaruh terhadap kualitas audit di KAP di Medan,Sumatera Utara 
Owner: Riset \& Jurnal Akuntansi

e-ISSN : 2548-9224 |p-ISSN : 2548-7507

Volume 5 Nomor 2, Agustus 2021

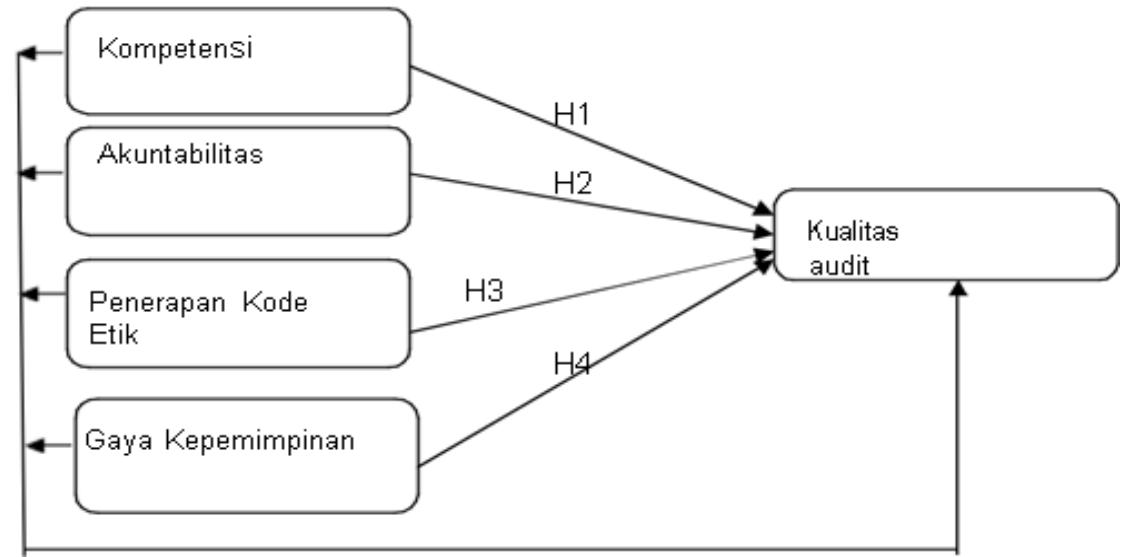

H5

Gambar 1. Kerangka Konseptual

\section{Jenis Penelitian}

\section{METODE PENELITIAN}

Jenis penelitian ini bertujuan menggunakan metode kuantitatif untuk penelitian kausalitas.Penelitian kausal digunakan untuk mengevaluasi hubungan antara variabel penelitian, atau untuk menguji pengaruh variabel terhadap variabel lain. Peneliti menggunakan desain penelitian ini untuk menyampaikan bukti empiris dan mengkaji pengaruh variabel kompetensi, akuntabilitas, penerapan kode etik, dan gaya kepemimpinan terhadap kualitas audit Kantor Akuntan Publik. Penelitian ini dilakukan di wilayah Medan.

\section{Populasi dan Sampel}

Populasi dalam penelitian ini adalah auditor Kantor Akuntan Publik Medan. Sampel untuk penelitian ini terdiri dari auditor KAP Medan. Teknik pengambilan sampel yang digunakan pada fast channel ini adalah dengan metode "proporsional simple random sampling", yaitu mengambil sampel secara acak dari setiap subkelompok.

\section{Jenis dan SumberData}

Penelitian kuantitatif adalah jenis penelitian yang digunakan, yaitu penggunaan metode survei dan penggunaan sumber data mentah. Data yang diperoleh langsung dari sumber data asli objek penelitian atau lokasi penelitian disebut data asli, dan metode yang bertujuan untuk memperoleh informasi dari sumber data dengan menggunakan pertanyaan tertulis untuk mengumpulkan data asli yang langsung diperoleh dari sumber data asli disebut metode survei. Jenis penelitian yang digunakan adalah data mentah.

\section{Variabel Penelitian dan Definisi Operasional}

Atribut, sifat, atau aspek yang dimiliki oleh orang atau objek dengan mutasi tertentu, yang digunakan peneliti untuk menggali dan menarik kesimpulan, disebut juga variabel. Dalam penelitian ini tinjauan dan evaluasi operasional dapat dilihat pada tabel berikut:

Tabel 1. Operasional Variabel Penelitian

\begin{tabular}{|l|l|l|l|}
\hline Variable Penelitian & Pengertian & Indikator & Skala \\
\hline Kompetensi & $\begin{array}{l}\text { Keseluruhan pengetahuan, } \\
\text { kemampuan atau keterampilan } \\
\text { dan sikap kerja ditambah } \\
\text { keunikan kepribadian yang } \\
\text { dimiliki seseorang.(Gea \& } \\
\text { Widhiyani, 2018) }\end{array}$ & 1. Pengetahuan & Skala \\
& & & \\
\end{tabular}


Owner: Riset \& Jurnal Akuntansi

e-ISSN : 2548-9224 |p-ISSN : 2548-7507

Volume 5 Nomor 2, Agustus 2021

DOI : https://doi.org/10.33395/owner.v5i2.414

\begin{tabular}{|c|c|c|c|}
\hline Variable Penelitian & Pengertian & Indikator & Skala \\
\hline Akuntabilitas & $\begin{array}{l}\text { suatu pengembangan dari rasa } \\
\text { tanggung jawab, suatu yang } \\
\text { lebih tinggi nilainya dari suatu } \\
\text { tanggung jawab kemudian } \\
\text { memuaskan atasan. }\end{array}$ & $\begin{array}{l}\text { 1. Motivasi } \\
\text { 2. Kewajiban }\end{array}$ & $\begin{array}{l}\text { Skala } \\
\text { Likert }\end{array}$ \\
\hline Penerapan Kode Etik & $\begin{array}{l}\text { Memilih prinsip dasar dan } \\
\text { norma etika profesi yang harus } \\
\text { diaplikasikan oleh setiap } \\
\text { personel dalam Kantor Akuntan } \\
\text { Publik (KAP) atau jaringan } \\
\text { KAP. (Primaraharjo \& } \\
\text { Handoko, 2011) }\end{array}$ & $\begin{array}{l}\text { 1. Auditor terhadap } \\
\text { atasannya } \\
\text { 2. Auditor terhadap } \\
\text { kliennya } \\
\text { 3. Auditor terhadap } \\
\text { masyarakat } \\
\text { 4. Auditor dengan } \\
\text { rekan kerjanya }\end{array}$ & $\begin{array}{l}\text { Skala } \\
\text { Likert }\end{array}$ \\
\hline Gaya Kepemimpinan & $\begin{array}{l}\text { Pola perilaku yang disiapkan } \\
\text { untuk mengintergrasikan target } \\
\text { organisasi dengan target } \\
\text { individu untuk mencapai target } \\
\text { tertentu.(Sugiarto, 2016) }\end{array}$ & $\begin{array}{l}\text { 1. Hubunga antara } \\
\text { pimpinan dan } \\
\text { bawahan } \\
\text { 2. Cara } \\
\text { mengambil } \\
\text { keputusan } \\
\text { 3. Carapandang } \\
\text { 4. Memberikan } \\
\text { penghargaan }\end{array}$ & $\begin{array}{l}\text { Skala } \\
\text { Likert }\end{array}$ \\
\hline Kualitas Audit & $\begin{array}{l}\text { Kualitas audit merupakan suatu } \\
\text { analisis yang teratur dan mandiri } \\
\text { untuk menilai apakah kualitas } \\
\text { aktivitas dan pencapaian hasil } \\
\text { sama dengan konsep yang sudah } \\
\text { disusun serta dapat dijalankan } \\
\text { secara efektif dalam pencapaian } \\
\text { tujuan. (Falatah \& Sukirno, } \\
\text { 2018) }\end{array}$ & $\begin{array}{l}\text { 1. Kesamaan } \\
\text { penyelidikan } \\
\text { dengan standar } \\
\text { audit } \\
\text { 2. Mutu laporan } \\
\text { hasil pemeriksaan }\end{array}$ & $\begin{array}{l}\text { Skala } \\
\text { Likert }\end{array}$ \\
\hline
\end{tabular}

Sumber: http://repository.unpas.ac.id/37954/4/BAB\%20III.pdf

\section{Metode Analisis Data}

Metode analisis data dalam penelitian ini menggunakan software WarpPLS, menggunakan metode Structural Equation Modelling (SEM) dan metode Partial Least Squares (PLS). Model persamaan struktural berdasarkan komponen atau varian adalah PLS. Menurut (Hermawan \& Hasibuan, 2016), PLS menjelaskan metode alternatif yang secara bertahap berubah dari metode SEM berbasis kovarian menjadi metode berbasis variasi. PLS lebih seperti model prediktif, sedangkan SEM berbasis kovarian biasanya menguji kausalitas / teori. Berikut tahapan analisis PLS yaitu:

1. Model struktur konseptual (model internal)

2. Model pengukuran konseptual (model eksternal)

3. Buat peta jalan (Konstruksi Diagram Jalur)

4. Ubah peta jalan ke model eksternal dari evaluasi system persamaan Evaluasi model eksternal digunakan untuk menentukan hubungan antara variabel laten dan indikator. (Oktarini \& Ramantha, 2016) Evaluasi model internal (Oktarini \& Ramantha, 2016) mengemukakan bahwa evaluasi model internal digunakan untuk menentukan hubungan antara variabel laten dan variabel lain dengan tingkat signifikan.

5. Perkiraan, Nilai yang dipertimbangkan dari koefisien jalur antara konstruksiharus mewarisi nilai yang signifikan. Dengan menggunakan program bootstrap, nilai yang berarti dapat 
ditemukan. Nilai yang muncul adalah nilai t hitung yang kemudian dipasangkan dengan $\mathrm{t}$ tabel. Jika nilai $t>t$ menunjukkan tingkat signifikansi 0,05 , maka nilai estimasi koefisien jalur tersebut signifikan.

6. Cocok, Pada bagian ini, berbagai kriteria kesesuaian dikembangkan untuk mengevaluasi penerapan model. Dalam PLS, goodness of fit dibagi menjadi dua bagian, yaitu sebagai berikut. Dikatakan bahwa beberapa kriteria evaluasi yang digunakan dalam mengevaluasi indikator model eksternal yaitu (Oktarini \& Ramantha, 2016):

- Validitas konvergen adalah faktor pemuatan 0,50 hingga 0,60.

- Validitas diskriminan nilai korelasi cross-loading dan variabel laten harus melebihi korelasi dengan variabel laten lainnya.

- Nilai AVE standar harus melebihi 0,50.

- Jika nilai reliabilitas komposit $\geq 0.70$ berarti baik.

\section{Model internal}

Nilai Q square > 0 menunjukkan bahwa model memiliki korelasi prediktif yang baik, sedangkan jika nilai Q square $\leq 0$ menunjukkan model kurang memiliki korelasi prediktif, maka digunakan variabel dependent $R$ square untuk mengukur goodness of fit model internal. Untuk model struktural, korelasi prediksi $Q$ square digunakan untuk mengukur kualitas pengamatan yang dihasilkan oleh model dan estimasi parameternya. Dalam penelitian ini pengujian hipotesis akan menggunakan regresi yang disesuaikan, dan dalam penelitian ini variabel independen juga akan mempengaruhi kualitas audit. Untuk menguji dan menjelaskan teori kausalitas, berbagai metode analisis regresi digunakan, dan hubungan terstruktur yang dikembangkan dari teori kausalitas dijelaskan. Persamaan regresi linier berganda adalah sebagai berikut:

$$
\mathrm{Y}=\alpha+\beta 1 \mathrm{X} 1+\beta 2 \mathrm{X} 2+\beta 3 \mathrm{X} 3+\beta 4 \mathrm{X} 4+\mathrm{e}
$$

Keterangan:

Y : KualitasAudit

$\alpha: \quad$ Konstanta

$\beta$ : $\quad$ Koefisien Regresi

$\mathrm{X} 1$ : Kompetensi
X2 : Akuntabilitas
X3 : Penerapan Kode Etik
X4 : Gaya Kepemimpinan
E : Error

\section{Lokasi Penelitian}

\section{HASIL}

Penelitian berikut dilakukan pada Kantor Akuntan Publik (KAP) di Medan. Data yang diperoleh dalam penelitian ini adalah data mentah yaitu datayang diperoleh dengan menyebarkan kuisioner kepada auditor Kantor Akuntan Publik Medan dapat dilihat pada tabel dibawah ini.

Tabel 2. Analisis Tingkat Pengembalian Kuesioner

\begin{tabular}{|c|l|c|c|}
\hline No & \multicolumn{1}{|c|}{ Keterangan } & Jumlah & Persentase \\
\hline 1 & Kuisioner yang dibagikan & 70 & $100 \%$ \\
\hline 2 & $\begin{array}{l}\text { Kuisioner yang tidak } \\
\text { dikembalikkan }\end{array}$ & 3 & $4.29 \%$ \\
\hline 3 & $\begin{array}{l}\text { Kuisioner yang dikembalikan } \\
\text { dan diolah }\end{array}$ & 67 & $95.71 \%$ \\
\hline & Jumlah & 70 & $95.71 \%$ \\
\hline
\end{tabular}

Sumber : Hasil Pengelolahan data (2020)

\section{Karakteristik Responden}

Hasil olah data berdasarkan kuisioner yang dikembalikan secara umum dapat dikelompokkan ke dalam beberapa kategori yaitu Jenis Kelamin, Usia, Jenjang Pendidikan, Jabatan dan Masa Kerja. Berikut gambaran umum karakteristik responden. 
Owner: Riset \& Jurnal Akuntansi

e-ISSN : 2548-9224 |p-ISSN : 2548-7507

Volume 5 Nomor 2, Agustus 2021

DOI : https://doi.org/10.33395/owner.v5i2.414

Tabel 3. Deskripsi Statistik Responden

\begin{tabular}{|c|c|c|c|}
\hline Karakteristik & Kategori & $\begin{array}{c}\text { frekuensi } \\
n=67\end{array}$ & valid \% \\
\hline \multirow[t]{2}{*}{ Jenis Kelamin } & Laki-laki & 39 & $58,2 \%$ \\
\hline & Perempuan & 28 & $41,7 \%$ \\
\hline \multirow{3}{*}{ Usia } & 20-34 tahun & 33 & $49,2 \%$ \\
\hline & $35-49$ tahun & 23 & $34,3 \%$ \\
\hline & $>49$ tahun & 11 & $16,4 \%$ \\
\hline \multirow{4}{*}{ Pendidikan } & D1-D3 & 6 & $8,95 \%$ \\
\hline & S1 & 40 & $59,7 \%$ \\
\hline & S2 & 20 & $29,8 \%$ \\
\hline & S3 & 1 & $1,49 \%$ \\
\hline \multirow{3}{*}{ Jabatan } & $\begin{array}{l}\text { Junior } \\
\text { Auditor }\end{array}$ & 31 & $46,2 \%$ \\
\hline & $\begin{array}{l}\text { Senior } \\
\text { Auditor }\end{array}$ & 23 & $34,3 \%$ \\
\hline & Manager & 13 & $19,4 \%$ \\
\hline \multirow{4}{*}{ Masa Kerja } & $<1$ tahun & 7 & $10,4 \%$ \\
\hline & 1-3 tahun & 25 & $37,3 \%$ \\
\hline & 3-5 tahun & 5 & $7,46 \%$ \\
\hline & $>5$ tahun & 30 & $44,7 \%$ \\
\hline
\end{tabular}

Sumber : Hasil Pengelolahan data (2020)

\section{Hasil Uji Partial Least Square (PLS)}

Uji PLS pada penelitian ini menggunakan evaluasi outer model dengan model reflektif dan evaluasi inner model dengan tingkat signifikansi $5 \%$

\section{Goodness of fit}

Pada pengujian ini dilakukan penyesuaian model melalui berbagai criteria Goodness of fit, dimana Goodness of fit diabagi kedalam dua bagian yaitu:

\section{Outer model}

Outer model dibagi menjadi dua, yaitu formatif dan reflektif. Dalam penelitian ini, indikator yang digunakan adalah indikator reflektif. Outer model dengan indikator reflektif dievaluasi dengan convergent dan discriminant validity dari indikatornya dan composite reliability untuk blok indikator

\section{Uji Convergent Validitiy}

Uji ini dilakukan untuk mengetahui kevaliditasan dari indikator-indikator yang digunakan. Indikator- indikator tersebur dinyatakan valid apanila nilai Loadings factor nya melebihi 0.50 dengan probabilitasnnya sebesar 5\%. Uji Loading factor masing-masing indikator dapat dilihat pada table berikut ini

Tabel 4. Uji Convergent Validity dan Uji Discriminant Validity

\begin{tabular}{|c|c|c|c|c|c|c|c|}
\hline Indikator & ompetensi & Akuntabili & $\begin{array}{l}\text { ode } \\
\text { tik }\end{array}$ & $\begin{array}{l}\text { Gaya } \\
\text { Kepemimpinan }\end{array}$ & $\begin{array}{l}\text { Kaulitas } \\
\text { Audit }\end{array}$ & $\begin{array}{l}\mathrm{P}- \\
\text { Value }\end{array}$ & Keterangan \\
\hline X1-1 & 0,518 & $-0,550$ & 0,104 & 0,404 & $-0,285$ & $<0,01$ & Valid \\
\hline $\mathrm{X} 1-2$ & 0,507 & $-0,111$ & $-0,190$ & $-0,408$ & 0,779 & $<0,01$ & Valid \\
\hline X1-3 & 0,863 & 0,073 & $-0,151$ & $-0,070$ & $-0,016$ & $<0,01$ & Valid \\
\hline
\end{tabular}


Owner: Riset \& Jurnal Akuntansi

e-ISSN : 2548-9224 |p-ISSN : 2548-7507

Volume 5 Nomor 2, Agustus 2021

DOI : https://doi.org/10.33395/owner.v5i2.414

\begin{tabular}{|c|c|c|c|c|c|c|c|}
\hline $\mathrm{X} 1-4$ & 0,578 & 0,483 & 0,300 & 0,100 & $-0,405$ & $<0,01$ & Valid \\
\hline X2-1 & $-0,128$ & 0,686 & 0,001 & $-0,404$ & 0,347 & $<0,01$ & Valid \\
\hline X2-2 & 0,049 & 0,439 & 0,270 & 0,124 & $-0,061$ & $<0,01$ & $\begin{array}{c}\text { Dapat } \\
\text { Dimaklumi }\end{array}$ \\
\hline $\mathrm{X} 2-3$ & 0,083 & 0,706 & $-0,099$ & 0,516 & $-0,521$ & $<0,01$ & Valid \\
\hline X2-4 & 0,011 & 0,674 & $-0,073$ & $-0,210$ & 0,232 & $<0,01$ & Valid \\
\hline X3-1 & 0,136 & $-0,032$ & 0,755 & 0,536 & $-0,656$ & $<0,01$ & Valid \\
\hline X3-2 & $-0,181$ & 0,004 & 0,780 & 0,690 & $-0,673$ & $<0,01$ & Valid \\
\hline X3-3 & $-0,331$ & $-0,092$ & 0,535 & 0,357 & $-0,322$ & $<0,01$ & Valid \\
\hline X3-4 & $-0,060$ & $-0,076$ & 0,529 & 0,716 & $-0,786$ & $<0,01$ & Valid \\
\hline X3-5 & 0,150 & 0,103 & 0,744 & $-0,223$ & 0,203 & $<0,01$ & $\begin{array}{c}\text { Dapat } \\
\text { Dimaklumi }\end{array}$ \\
\hline X3-6 & 0,108 & 0,007 & 0,390 & $-0,811$ & 1,025 & $<0,01$ & Valid \\
\hline X3-7 & 0,341 & $-0,070$ & 0,453 & $-1,064$ & 0,969 & $<0,01$ & Valid \\
\hline X3-8 & $-0,084$ & 0,102 & 0,640 & $-0,867$ & 0,976 & $<0,01$ & Valid \\
\hline X4-1 & $-0,017$ & $-0,143$ & 0,278 & 0,636 & $-1,298$ & $<0,01$ & Valid \\
\hline X4-2 & 0,313 & $-0,193$ & 0,093 & 0,619 & $-1,037$ & $<0,01$ & Valid \\
\hline $\mathrm{X} 4-3$ & $-0,032$ & 0,020 & $-0,234$ & 0,848 & $-0,285$ & $<0,01$ & Valid \\
\hline $\mathrm{X} 4-4$ & $-0,223$ & 0,263 & $-0,035$ & 0,759 & $-0,510$ & $<0,01$ & Valid \\
\hline $\mathrm{X} 4-5$ & $-0,073$ & 0,094 & $-0,143$ & 0,674 & 0,453 & $<0,01$ & Valid \\
\hline $\mathrm{X} 4-6$ & 0,433 & $-0,091$ & $-0,293$ & 0,733 & 0,748 & $<0,01$ & Valid \\
\hline $\mathrm{X} 4-7$ & $-0,208$ & 0,050 & 0,253 & 0,632 & 1,262 & $<0,01$ & Valid \\
\hline X4-8 & $-0,159$ & $-0,040$ & 0,173 & 0,778 & 0,618 & $<0,01$ & Valid \\
\hline $\mathrm{Y} 1$ & $-0,073$ & 0,094 & $-0,143$ & 0,314 & 0,713 & $<0,01$ & Valid \\
\hline $\mathrm{Y} 2$ & 0,433 & $-0,091$ & $-0,293$ & 0,149 & 0,778 & $<0,01$ & Valid \\
\hline Y3 & $-0,208$ & 0,050 & 0,253 & $-0,660$ & 0,736 & $<0,01$ & Valid \\
\hline Y4 & $-0,159$ & $-0,040$ & 0,173 & 0,175 & 0,832 & $<0,01$ & Valid \\
\hline
\end{tabular}

Sumber : Hasil pengelolahan data (2020)

Berdasarkan tabel 3 pada uji Convergent Validity hampir semua variabel nya memenuhi syarat baik variabel kompetensi, akuntabilitas, Kode Etik, Gaya Kepemimpinan maupun kualitas audit semua memenuhi, hanya X2-2 dan X3-5 yang tidak memenuhi akan tetapi masih dapat dimaklumi sehingga semua indikator yang ada dapat diikut sertakan kedalam analisis berikutnya.

\section{Uji discriminant validity}

Uji berikut ini dilakukan untuk menguji apakah ada atau tidaknya korelasi antara tiap-tiap indikator dengan variabel laten yang ada. Validitas indikator yang ada dinyatakan valid apabila jika nilai korelasi cross loading lebih besar dari pada nilai korelasi variabel latennya. Nilai korelasinya dapat dijelaskan pada variabel berikut ini.

Berdasarkan tabel dengan uji validitas diskriminan diatas, terlihat bahwa selisih nilai korelasi lintas beban indeks kemampuan lebih besar dari nilai korelasi lintas beban variabel lain 0,5070,863 , yang menunjukkan bahwa indeks kemampuan yang diteliti efektif. Nilai item cross load miscellaneous pada indeks akuntabilitas lebih besar dari nilai korelasi cross load variabel potensial lainnya sebesar 0.674-0.706, sehingga indeks akuntabilitas dinyatakan efektif. Nilai korelasi cross loading pada indikator "Kode Etik" lebih besar dari pada nilai korelasi indikator variabel laten lainnya sebesar 0,529-0,780, sehingga indikator "Kode Etik" dinyatakan efektif. Nilai korelasi cross loading pada indikator Leadership Style lebih besar dari nilai korelasi cross loading variabel potensial lainnya sebesar 0.619-0.848, sehingga indikator Leadership Style dinyatakan valid. Nilai 
Owner: Riset \& Jurnal Akuntansi

e-ISSN : 2548-9224 |p-ISSN : 2548-7507

Volume 5 Nomor 2, Agustus 2021

DOI : https://doi.org/10.33395/owner.v5i2.414

Korelasi cross loading variabel Kualitas Audit lebih besar dari nilai korelasi cross loading variabel laten lainnya sebesar 0.618-0.832 maka indikator Kualitas Audit dinyatakan Valid.

\section{Average Variance Extracted (AVE)}

Tabel 6. Average Variance Extracted (AVE)

\begin{tabular}{|l|l|}
\hline Variabel & AVE \\
\hline Kompetensi & 0.401 \\
\hline Akuntabilitas & 0.404 \\
\hline Kode Etik & 0.386 \\
\hline Gaya Kepemimpinan & 0.514 \\
\hline Kualitas Audit & 0.587 \\
\hline
\end{tabular}

Sumber : Hasil Penelolahan data(2020)

Berdasarkan pada tabel 5, hasil pengujian Average Variance Extraction (AVE) menunjukkan nilai kapabilitas AVE sebesar 0,401, nilai akuntabilitas AVE sebesar 0,404, nilai etika AVE sebesar 0,386, nilai AVE Leadership Style sebesar 0,514, dan nilai AVE Audit Quality sebesar 0,587. Nilai AVE variabel harus lebih besar dari 0,5 agar dianggap valid. Dalam hal ini, hanya variabel gaya kepemimpinan dan kualitas audit yang dianggap valid karena melebihi 0,5 .

\section{Composite Reliability}

Uji composite reliability dilakukan untuk mengukur seberapa reliabel suatu variable yang ada. Seluruh nilai variabel dinyatakan reliabel apabila nilai loadingnya diatas 0.70 . Nilai composite reliability setiap variabel dapat dilihat pada table berikut ini.

Tabel 7. Composite Reability

\begin{tabular}{|l|l|l|}
\hline Variabel & Composite Reability & Keterangan \\
\hline Kompetensi & 0.717 & Reliable \\
\hline Akuntabilitas & 0.725 & Reliable \\
\hline Kode Etik & 0.827 & Reliable \\
\hline Gaya Kepemimpinan & 0.893 & Reliable \\
\hline Kualitas Audit & 0.850 & Reliable \\
\hline
\end{tabular}

Sumber : Hasil Penelolahan Data (2020)

\section{Evaluasi Inner Model}

Evaluasi inner model dilakukan dengan uji bootstrapping yang menghasilkan nilai koefisien determinasi R square, Q square, path coefficients, latent variable correlations. Hasil evaluasi inner model dijelaskan sebagai berikut.

\section{Koefisien Determinasi $R$-Square}

Nilai $R$-Square diteliti untuk mengetahui sejauh mana signifikansi suatu variabel dari variabel laten.

Tabel 8. Adjusted R-Square

\begin{tabular}{|l|l|}
\hline Variabel & R-Square \\
\hline Kualitas Audit & 0,866 \\
\hline Kompetensi*Akuntabilitas*KodeEtik*Gaya Kepemimpinan & \\
\hline
\end{tabular}

Sumber : Hasil Pengelolahan Data (2020)

Berdasarkan data table adjusted $R$-Square nilai $R$-Square nya adalah 0.866 . Hasil ini dapat diartikan bahwa sebesar $86.6 \%$ variabel kualitas audit dapat dijelaskan menggunakan variabel Kompetensi, Akuntabilitas, Kode Etik dan Gaya Kepemimpinan sedangkan sisanya sebesar $13.4 \%$ dapat dijelaskan menggunakan variabel lain diluar variabel yang diteliti. 


\section{Q-Square}

Suatu model dianggap mempunyai nilai yang relevan jika nilai $Q$-Square lebih besar dari 0 . Hasil perhitungan $Q$-Square pada penelitian ini adalah 0,865 . Hal ini berarti model dalam penelitian ini layak untuk menjelaskan variabel endogen yaitu kualitas audit.

\section{Pengujian Hipotesis}

Hubungan diantara variabel laten dalam penelitian dapat dilihat dari hasil koefisien jalur (path coefficient) dan tingkat signifikansinya dilihat berdasarkan ( $p$-value). Pengujian hipotesis penelitian berikut daoat dilihat dari :

1. Jika thitung $>\mathrm{t}$ tabel atau tingkat signifikansi $<\alpha=0,05$ maka hipotesis diterima.

2. Jika thitung $<\mathrm{t}$ tabel atau tingkat signifikansi $>\alpha=0,05$ maka hipotesis tidak didukung.

Path Coefficients berfungsi untuk menguji pengaruh antara variabel yang diuji dan menjelaskan hubungan antar variabelnya. Hasil nya dapat dilihat melalui tabel berikut ini.

Tabel 9. Hasil Estimasi Path Coefficients

\begin{tabular}{|l|c|c|c|c|}
\hline \multicolumn{1}{|c|}{ Hipotesis } & $\begin{array}{c}\text { Path } \\
\text { Coefficients }\end{array}$ & $\begin{array}{c}\text { Std. } \\
\text { Errors }\end{array}$ & $\begin{array}{c}P- \\
\text { Value }\end{array}$ & Keterangan \\
\hline Kompetensi>Kualitas Audit & -0.020 & 0.121 & 0.435 & $\begin{array}{c}\text { Tidak } \\
\text { Signifikan }\end{array}$ \\
\hline Akuntabilitas>Kualitas Audit & 0.074 & 0.119 & 0.269 & $\begin{array}{c}\text { Tidak } \\
\text { Signifikan }\end{array}$ \\
\hline Kode-Etik>Kualitas Audit & 0.022 & 0.121 & 0.429 & $\begin{array}{c}\text { Tidak } \\
\text { Signifikan }\end{array}$ \\
\hline $\begin{array}{l}\text { Gaya } \\
\text { Kempemimpinan>Kualitas } \\
\text { Audit }\end{array}$ & 0.895 & 0.091 & $<0.001$ & \begin{tabular}{c} 
Signifikan \\
\hline
\end{tabular} \\
\hline
\end{tabular}

Sumber : Hasil Pengelolahan Data (2020)

\section{PEMBAHASAN \\ Kompetensi berpengaruh terhadap kualitas audit (hipotesis 1)}

Hasil penelitian menunjukkan bahwa hipotesis 1 ditolak, koefisien $-0,020$, dan tingkat signifikansi 0,435 lebih besar dari 0,05. Hasil ini tidak sejalan dengan teori yang ada bahwa kemampuan mempengaruhi kualitas audit. Hasil penelitian ini sejalan dengan penelitian peneliti sebelumnya (Muslimin, 2018) bahwa variabel sikap skeptis, independensi, kompetensi dan pengalaman auditor tidak mempengaruhi kualitas audit.

Hal ini dikarenakan sebagian besar yang diteliti dalam bidang ini adalah auditor junior. Selain itu, sebagian besar yang diwawancarai dalam penelitian ini memiliki jam kerja audit kurang dari 5 tahun, sehingga jawaban yang diberikan oleh narasumber terkait variabel pengetahuan dan pengalaman tidak yakin. Hasil audit biasanya baik dari kemampuan auditor dan kejujuran kerjanya. Auditor yang baik tentunya harus memiliki kedua aspek tersebut, agar audit yang dilakukan dapat memperoleh hasil berdasarkan fakta yang ada.

\section{Akuntabilitas berpengaruh terhadap kualitas audit (hipotesis 2)}

Hasil penelitian menunjukkan bahwa hipotesis 2 ditolak, koefisien 0,074, tingkat signifikansi 0,269 , dan tingkat signifikansi lebih dari 0,05. Hasil ini tidak sejalan dengan teori penelitian sebelumnya yang dilakukan oleh (Dewi \& Sudana, 2018) bahwa akuntabilitas mempengaruhi kualitas audit. Hasil penelitian ini juga sama dengan teori yang dipaparkan penelitian peneliti sebelumnya yaitu (Wahyuni, 2018) dimana hipotesis dalam jurnal juga menyatakan, sistem akuntabilitas tidak berpengaruh terhadap kualitas audit. Hal ini dikarenakan sebagian besar penelitian di bidang ini adalah auditor junior yang bekerja kurang dari 5 tahun, sehingga jawaban terkait variabel motivasi dan kewajiban kurang pasti dikarenakan auditor yang jam terbangnya masih sedikit. 


\section{Kode Etik berpengaruh terhadap kualitas audit (hipotesis 3)}

Hasil penelitian menunjukkan bahwa hipotesis 3 ditolak, koefisien 0,022, tingkat signifikansi 0,429 , dan tingkat signifikansi lebih dari 0,05 . Hasil ini tidak sejalan dengan teori penelitian (Futri \& Juliarsa, 2014) bahwa etika mempengaruhi kualitas audit. Hasil penelitian ini sejalan dengan pandangan peneliti sebelumnya (Alfiati, 2017) Dalam jurnal tersebut, hasil hipotesis juga menunjukkan bahwa kode etik Tidak berdampak pada kualitas audit. Hal ini dikarenakan penelitian pada daerah tertentu yang diwawancarai adalah auditor junior dimana kurangnya jumlah auditor yang ada menjadi masalah utama dalam penelitian ini, sehingga jawaban terkait prinsip dan variabel etika kurang pasti.

\section{Gaya Kepemimpinan berpengaruh terhadap kualitas audit (hipotesis 4)}

Hasil penelitian menunjukkan bahwa hipotesis 4 diterima, koefisien 0,895, signifikansi kurang dari 0,001 dan kurang dari 0,05. Artinya setiap peningkatan gaya kepemimpinan akan meningkatkan kualitas audit sebesar 0,895 . Hasil ini sejalan dengan teori Penelitian (Wardana \& Ariyanto, 2016) menunjukkan bahwa gaya kepemimpinan berpengaruh positif dan signifikan terhadap kualitas audit bahwa gaya kepemimpinan mempengaruhi kualitas audit. Hasil penelitian ini sejalan dengan teori penelitian sebelumnya (Nuraini, 2016) dimana Gaya Kepemimpinan berpengaruh terhadap kualitas audit.

\section{KESIMPULAN}

Berlandaskan hasil dari yang kami teliti, maka bisa disimpulkan sebagai bahwa Kompetensi, Akuntabilitas dan Kode Etik Auditor Akuntan Publik Medan tidak mempengaruhi Kualitas audit, akan tetapi Gaya Kepemimpinan berpengaruh terhadap Kualitas Audit. Saran kami bagi peneliti kedepannya untuk melengkapi kekuranagn penelitian kami berdasarkan dari penelitian yang kami uraikan sebagai berikut: (1) Pimpinan yang dapat berkomunikasi dengan bawahannya secara lancar akan menjadi faktor yang penting dalam menciptakan hasil audit yang baik; (2) Untuk peneliti selanjutnya diharapkan dapat menggunakan variable lainnya pada penelitian selanjutnya agar dapat meneliti faktor lain yang bisa mempengaruhi kualitas audit seorang auditor; (3) Untuk peneliti selanjutnya alangkah baiknya tidak hanya menggunakan kuisioner saja akan tetapi dapat melengkapinya dengan metode lain atau wawancara untuk menghasilkan data yang valid agar sesuai dengan kenyataan yang ada.

\section{REFERENSI}

Adi, F. S. (2016). PENGARUH PROFESIONALISME, PENERAPAN KODE ETIK, DAN TIME BUDGET PRESSURE TERHADAP KUALITAS AUDIT (Studi Empiris pada Auditor di KAP Kota Surakarta dan Yogyakarta).

Alfiati, R. (2017). PENGARUH ETIKA AUDITOR, SKEPTISISME PROFESIONAL DAN KOMPETENSI AUDITOR TERHADAP KUALITAS AUDIT (Studi Empiris pada Kantor Inspektorat Provinsi Sumatera Barat ).

Ardini, L. (2010). Pengaruh Kompetensi, Independensi, Akuntabilitas Dan Motivasi Terhadap Kualitas Audit. Majalah Ekonomi Tahun XX, (3), 6-7.

Dahlia, L., \& Octavianty, E. (2016). Profesional Auditor Terhadap Kualitas Audit. Jiafe(Jurnal Ilmiah Akuntansi Fakultas Ekonomi), 2(1), 16-37.

Dewi, N. M. W. I., \& Sudana, P. (2018). Pengaruh Pengalaman, Due Professional Care dan Akuntabilitas Pada Kualitas Audit. E-Jurnal Akuntansi, 22, 438. https://doi.org/10.24843/eja.2018.v22.i01.p17

Fahdi, M. (2018). Pengaruh independensi dan kompetensi terhadap kualitas audit (Studi Empiris Pada Inspektorat Se Provinsi Riau). Jurnal Valuta, 4(2), 86-95. Retrieved from https://journal.uir.ac.id/index.php/valuta/article/view/2583/1458

Falatah, H. F., \& Sukirno, S. (2018). PENGARUH KOMPETENSI, INDEPENDENSI DAN MORAL REASONING AUDITOR TERHADAP KUALITAS AUDIT (Studi Pada Kantor Inspektorat Daerah Di Propinsi Daerah Istimewa Yogyakarta). Nominal, Barometer Riset Akuntansi Dan Manajemen, 7(1). https://doi.org/10.21831/nominal.v7i1.19361

Futri, P. S., \& Juliarsa, G. (2014). PENGARUH INDEPENDENSI, PROFESIONALISME, 
TINGKAT PENDIDIKAN, ETIKA PROFESI, PENGALAMAN, DAN KEPUASAN KERJA AUDITOR PADA KUALITAS AUDIT KANTOR AKUNTAN PUBLIK DI BALI. E-Jurnal Akuntansi Universitas Udayana, 7.2, 444-461. https://doi.org/10.1111/j.13652761.1986.tb01041.x

Gea, F., \& Widhiyani, N. L. S. (2018). Etika Auditor Sebagai Pemoderasi Pengaruh Kompetensi dan Tekanan Anggaran Waktu Terhadap Kualitas Audit. E-Jurnal Akuntansi, 24(1), 311-338. https://doi.org/10.24843/EJA.2018.v24.i01.p12

Harjanto, A. P. (2014). PENGARUH KOMPETENSI, INDEPENDENSI, OBJEKTIVITAS, AKUNTABILITAS DAN INTEGRITAS TERHADAP KUALITAS AUDIT DENGAN ETIKA AUDITOR SEBAGAI VARIABEL MODERASI( Studi Empiris KAP di Semarang ).

Hermawan, R. T., \& Hasibuan, S. (2016). 182908-ID-analisis-pengaruh-tingkat-pengalaman-dan. Analisis Pengaruh Tingkat Pengalaman Dan Coaching Style Terhadap Kualitas Kepemimpinan Manajer Proyek Dalam Upaya Peningkatan Produktivitas Di Pt. Jci, XI(1), 84-97.

Ilham, M., Rai, W., Sigit, S., \& Surono, E. (2019). Pengaruh Kompetensi , Integritas , Dan Motivasi Terhadap Kualitas Audit ( Studi Empiris Pada Inspektorat Kota Bogor ). Audit, 15. Retrieved from http://jom.unpak.ac.id/index.php/akuntansi/article/download/1060/817

Ilmiyati, F., \& Suhardjo, Y. (2012). PENGARUH AKUNTABILITAS DAN KOMPETENSI AUDITOR TERHADAP KUALITAS AUDIT (Studi Empiris Pada Kantor Akuntan Publik di Semarang). Juraksi, 1(1), 43-56.

Mardisar, D., \& Sari, N. (2007). PENGARUH AKUNTABILITAS DAN PENGETAHUAN TERHADAP KUALITAS HASIL KERJA AUDITOR DIANI MARDISAR dan RIA NELLY SARI Universitas Riau. Simposium Nasional Akuntansi X2, AUEP-11, 1-25.

Muslimin, F. A. (2018). Pengaruh Sikap Skeptis, Independensi, Penerapan Kode Etik, Akuntabilitas, Kompetensi, dan Pengalaman Auditor Terhadap Kualitas Audit ( Studi pada Kantor Akuntan Publik di kota Surakarta dan Semarang ).

Nainggolan, E. P., \& Abdullah, I. (2016). Pengaruh Akuntabilitas, Objektivitas Terhadap Kualitas Audit Dengan Etika Auditor Sebagai Variabel Moderasi Study Kasus Pada Kantor Akuntan Publik Di Kota Medan. Human Falah, 3(1), 94-112.

Nuraini, L. (2016). PENGARUH INDEPENDENSI, GAYA KEPEMIMPINAN DAN BUDAYA ORGANISASI TERHADAP KINERJA AUDITOR (Studi Empiris Pada Kantor Akuntan Publik Yogyakarta dan Solo).

Oktarini, K., \& Ramantha, I. (2016). Pengaruh Pengalaman Kerja Dan Kepatuhan Terhadap Kode Etik Pada Kualitas Audit Melalui Skeptisisme Profesional Auditor. E-Jurnal Akuntansi, 15(1), 754-783.

Primaraharjo, B., \& Handoko, J. (2011). Pengaruh Kode Etik Profesi Akuntan Publik Terhadap Kualitas Audit Auditor Independen Di Surabaya. Jurnal Akuntansi Kontemporer, 3(1), 243811. https://doi.org/10.33508/jako.v3i1.1013

Purnomo, S. D. (2017). PENGARUH INTEGRITAS, KOMPETENSI, OBJEKTIVITAS, PROFESIONALISME, DAN DUE PROFESSIONAL CARE TERHADAP KUALITAS AUDIT (Studi Empiris Persepsi Auditor pada KAP di Surakarta dan Yogyakarta).

Saputra, P. I. P., Sujana, E., \& Werastuti, D. N. S. (2015). Pengaruh Gaya Kepemimpinan, Kepuasan Kerja, dan Motivasi Kerja Terhadap Kinerja Auditor (Studi Empiris Pada Kantor Akuntan Publik di Provinsi Bali). Jurnal Ilmiah Mahasiswa Akutansi Undiksha, 3(1).

Setiyadi, I. N. (2016). Pengaruh Gaya Kepemimpinan, Komitmen Organisasi, Dan Pemahaman Sistem Informasi Akuntansi Pada Kinerja Auditor Kantor Akuntan Publik. E-Jurnal Akuntansi, 17(3), 1953-1980.

Sugiarto, C. (2016). Analisis Pengaruh Gaya Kepemimpinan, Komunikasi Internal, Budaya Organisasi Dan Disiplin Kerja Terhadap Efektivitas Kerja Karyawan Koperasi Agrobisnis Tarutama Nusantara (Kopa Ttn) Jember. Bisma Jurnal Bisnis Dan Manajemen, 10(3), 240251.

Tjun, L. T., Marpaung, E. I., \& Setiawan, S. (2012). The magnetic resonance imaging appearances in Kienböck's disease. Journal of Hand Surgery: European Volume, 4(1), 33-56. https://doi.org/10.1177/1753193416664491 
Owner: Riset \& Jurnal Akuntansi

e-ISSN : 2548-9224 |p-ISSN : 2548-7507

Volume 5 Nomor 2, Agustus 2021

DOI : https://doi.org/10.33395/owner.v5i2.414

Trisnaningsih, S. (2007). INDEPENDENSI AUDITOR DAN KOMITMEN ORGANISASI SEBAGAI MEDIASI PENGARUH PEMAHAMAN GOOD GOVERNANCE, GAYA KEPEMIMPINAN DAN BUDAYA ORGANISASI TERHADAP KINERJA AUDITOR. Simposium Nasional Akuntansi $X, A M P K-02,1-56$.

Wahyuni, S. E. (2018). PENGARUH INDEPENDENSI, KOMPETENSI, AKUNTABILITAS DAN PENGALAMAN KERJA TERHADAP KUALITAS AUDIT (Studi Empiris pada Kantor Akuntan Publik di Wilayah Surakarta dan Yogyakarta). Retrieved from http://dx.doi.org/10.1016/j.cirp.2016.06.001\%0Ahttp://dx.doi.org/10.1016/j.powtec.2016.12 .055\%0Ahttps://doi.org/10.1016/j.ijfatigue.2019.02.006\%0Ahttps://doi.org/10.1016/j.matlet .2019.04.024\%0Ahttps://doi.org/10.1016/j.matlet.2019.127252\%0Ahttp://dx.doi.o

Wardana, M. A., \& Ariyanto, D. (2016). PENGARUH GAYA KEPEMIMPINAN TRANSFORMASIONAL , OBJEKTIVITAS , INTEGRITAS DAN ETIKA AUDITOR TERHADAP KUALITAS AUDIT Fakultas Ekonomi dan Bisnis Universitas Udayana ( Unud ), Bali, Indonesia Setiap Kantor Akuntan Publik ( KAP) menginginkan untuk memiliki s. 948-976. 